CLINICAL STUDY

\title{
Salvage therapy with temozolomide in patients with aggressive or metastatic pituitary adenomas: experience in six cases
}

\author{
Marco Losa ${ }^{1}$, Elena Mazza ${ }^{2}$, Maria Rosa Terreni ${ }^{3}$, Ann McCormack ${ }^{4}$, Anthony J Gill ${ }^{5,6}$, Micaela Motta ${ }^{2}$, \\ Maria Giulia Cangi ${ }^{3}$, Anna Talarico ${ }^{3}$, Pietro Mortini ${ }^{1}$ and Michele Reni ${ }^{2}$ \\ ${ }^{1}$ Pituitary Unit, Department of Neurosurgery, ${ }^{2}$ Department of Oncology and ${ }^{3}$ Pathology Unit, Istituto Scientifico San Raffaele, Università Vita-Salute, \\ Via Olgettina 60, 20132 Milano, Italy, ${ }^{4}$ Hormones and Cancer Group, Cancer Genetics Unit, Kolling Institute of Medical Research and ${ }^{5}$ Department of \\ Anatomical Pathology, Royal North Shore Hospital, Sydney, New South Wales 2065, Australia and ${ }^{6}$ University of Sydney, Sydney, New South Wales \\ 2006, Australia
}

(Correspondence should be addressed to M Losa; Email: losa.marco@hsrit)

\begin{abstract}
Objective: The prognosis of either pituitary carcinoma or aggressive pituitary adenoma resistant to standard therapies is poor. We assessed the efficacy of treatment with temozolomide, an oral secondgeneration alkylating agent, in a consecutive series of six patients with aggressive pituitary adenomas. Design: This was a 1-year prospective study of temozolomide therapy in six consecutive patients with pituitary carcinoma (one case) or atypical pituitary adenoma (five cases) resistant to standard therapies. There were three males and three females. Age at enrollment ranged between 52 and 64 years. Temozolomide was given orally at a dose of $150-200 \mathrm{mg} / \mathrm{m}^{2}$ per day for 5 days every 4 weeks for a maximum of 12 cycles.

Methods: Response assessment was based on measurable change in tumor size, as assessed on magnetic resonance imaging, and hormone levels. Response was defined as reduction of at least $50 \%$ of tumor size and hormone levels.

Results: Four patients completed the 12 cycles of temozolomide treatment, as planned. Two patients stopped the drug after 3 and 6 months respectively because of the progression of disease. Two patients responded to temozolomide, while the remaining two patients had stable disease. Immunohistochemistry for $O^{6}$-methylguanine-DNA methyltransferase (MGMT) in tumor sample showed a partial association with treatment response.

Conclusions: Temozolomide treatment has a wide range of efficacy in patients with pituitary carcinoma or locally aggressive pituitary adenoma. Positive staining for MGMT seems likely to predict a lower chance of response.
\end{abstract}

European Journal of Endocrinology 163 843-851

\section{Introduction}

Pituitary adenomas comprise nearly $15 \%$ of intracranial neoplasm, and clinically evident local invasion is present in about one-third of cases (1). In most cases, pituitary adenomas are benign slow-growing tumors. However, some tumors are characterized by a fast rate of growth and are resistant to standard medical, surgical, and radiation treatments. According to the WHO 2004 Classification of Endocrine Tumors (2), a pituitary adenoma characterized by the presence of invasive growth and combinations of increased mitotic activity, a Ki-67 labeling index $>3 \%$, and p53 immunoreactivity may be classified as atypical. Using WHO 2004 terminology, the term 'pituitary carcinoma' is restricted to tumors with proven cerebrospinal and/or systemic metastases (2). The incidence of pituitary carcinomas is $<0.5 \%$ of symptomatic and $0.2 \%$ of operated pituitary tumors $(2,3)$. The prognosis of pituitary carcinoma is poor, the mean survival being $<4$ years (4), and accelerated progression of the disease has been described (5). The response to various treatments is usually poor, and no consistent therapeutic scheme has been developed $(4,5)$.

Temozolomide is an oral second-generation alkylating agent that spontaneously undergoes chemical conversion to the cytotoxic metabolite 5-(3 methyl-1-triazeno) imidazole-4-carboxamide at physiological $\mathrm{pH}$, without metabolic conversion. Temozolomide depletes the DNA repair enzyme $O^{6}$-methylguanine-DNA methyltransferase (MGMT) in various cell types. The drug penetrates the blood-brain barrier effectively (6) and has antineoplastic activity against high-grade gliomas and cerebral metastases of malignant melanoma $(7,8)$. Moreover, the drug has been shown to possess activity against malignant neuroendocrine tumors (9).

Preliminary reports demonstrated a good response to temozolomide treatment in patients with either 
pituitary carcinoma (10-12) or aggressive pituitary adenomas resistant to standard therapies (12-14). Herewith, we report our experience with temozolomide treatment and its relationship to MGMT expression in a series of six patients with aggressive pituitary tumors.

\section{Subjects and methods}

\section{Patients}

Between September 2006 and November 2008, six consecutive patients with either pituitary carcinoma (one case) or atypical pituitary adenoma that showed local growth despite previous surgery, radiation and standard medical therapies (five cases) were offered salvage treatment with temozolomide, based on case reports showing a good response in similar cases $(10,11,13,14)$.

The main clinical and demographic characteristics of the patients are depicted in Table 1. There were three males and three females. Age at enrollment ranged between 52 and 64 years. The median time at first diagnosis of pituitary adenoma was 7 years (range 4-25 years) before starting temozolomide therapy. Three patients had Cushing's disease, two patients had prolactin (PRL)-secreting adenoma, and one had Nelson's syndrome. All the patients had already received several treatments at our hospital or other hospitals (Table 1), but the pituitary tumor showed either liquoral dissemination (one case) or rapid local growth after recurrence of disease. The two patients with PRLsecreting adenoma had resistance to high doses of cabergoline $(3.5 \mathrm{mg} /$ week). Octreotide-LAR (30 mg) was attempted without success in one patient with Cushing's disease and one with Nelson's syndrome. All the patients had previously undergone at least one radiation treatment, either fractionated radiotherapy (three patients), stereotactic radiotherapy with a linear accelerator (one patient), or gamma knife radiosurgery (three patients). Four patients received more than one radiation treatment (Table 1). In all the patients, radiation was performed after surgical debulking of the tumor and initially led to reduction in the residual tumor in four patients, whereas initial stabilization of the tumor was obtained in the other two cases.

Before treatment with temozolomide, there was a clear radiological evidence of tumor regrowth in each patient. In Patient \#1, the lesion extended into the left cavernous sinus and destroyed the sellar floor growing into both the nasal fossa and the left orbit. This patient complained of severe headache, nasal obstruction, and complete left ophthalmoplegia since 4 months. Transsphenoidal biopsy of the mass showed a poorly differentiated pituitary tumor characterized by area of necrosis and high mitotic activity. Patient \#2 developed signs and symptoms of hypercortisolism, and a scheduled magnetic resonance imaging (MRI) showed several contrast-enhancing lesions disseminated along the liquoral pathway (Fig. 1). Transcranial biopsy of a left frontal nodule confirmed metastasis from a pituitary adenoma that stained positive for ACTH. The largest metastasis, which was located just in front of the pons, was treated with gamma knife radiosurgery. Patient \#3 had worsening hyperpigmentation, rising ACTH levels, and demonstration of progressive growth of the pituitary lesion that extended into both cavernous sinuses and had eroded the sellar floor growing within the sphenoid sinus. Patient \#4 had clinical and biochemical recurrence of hypercortisolism 1 year after the second course of fractionated radiotherapy and a mild growth of residual tumor in both cavernous sinuses. Patient \#5 had rising PRL levels and further increase in the pituitary tumor that occupied the sella turcica with upward and anterior extension. Another part of the tumor had eroded the skull base and occupied the sphenoid sinus and part of the ethmoid space (Fig. 1). Except for slight headache, the patient was still asymptomatic. Patient \#6 presented with rapid rise of PRL levels, regrowth of the tumor within the left cavernous sinus, severe headache not responding to common analgesics and gabapentin 2 years after a second gamma knife treatment. She also had paralysis of the sixth left cranial nerve causing diplopia since 4 months.

Table 1 Demographic and clinical characteristics of six patients treated with temozolomide because of pituitary carcinoma or atypical pituitary adenoma.

\begin{tabular}{llcclcc}
\hline $\begin{array}{l}\text { Patient } \\
\text { number }\end{array}$ & Sex & Age & $\begin{array}{c}\text { Age at initial } \\
\text { treatment }\end{array}$ & $\begin{array}{l}\text { Clinical } \\
\text { diagnosis }\end{array}$ & $\begin{array}{c}\text { Presence of } \\
\text { metastasis }\end{array}$ & $\begin{array}{l}\text { Previous } \\
\text { treatments }\end{array}$ \\
\hline 1 & Male & 64 & 57 & Cushing & No & 2 TNS, 2 SR, SSA, DA \\
2 & Male & 52 & 46 & Cushing & Yes & 1 TC, 2 TNS, 1 Rx, 1 GK \\
3 & Female & 55 & 40 & Nelson & No & 2 GK, SSA \\
4 & Female & 53 & 28 & Cushing & No & 2 TNS, 2 Rx \\
5 & Male & 62 & 55 & PRL-oma & No & DA, 1 TNS, 1 Rx \\
6 & Female & 57 & 53 & PRL-oma & No & DA, 2 TNS, 1 GK \\
\hline
\end{tabular}

DA, dopamine agonists; GK, gamma knife radiosurgery; PRL-oma, PRL-secreting adenoma; Rx, fractionated radiotherapy; SR, stereotactic radiotherapy with a linear accelerator; SSA, somatostatin analogs; TNS, transsphenoidal surgery; TC, transcranial surgery.

a This patient had already performed two transsphenoidal surgical procedures for Cushing's disease without success before performing bilateral adrenalectomy. 

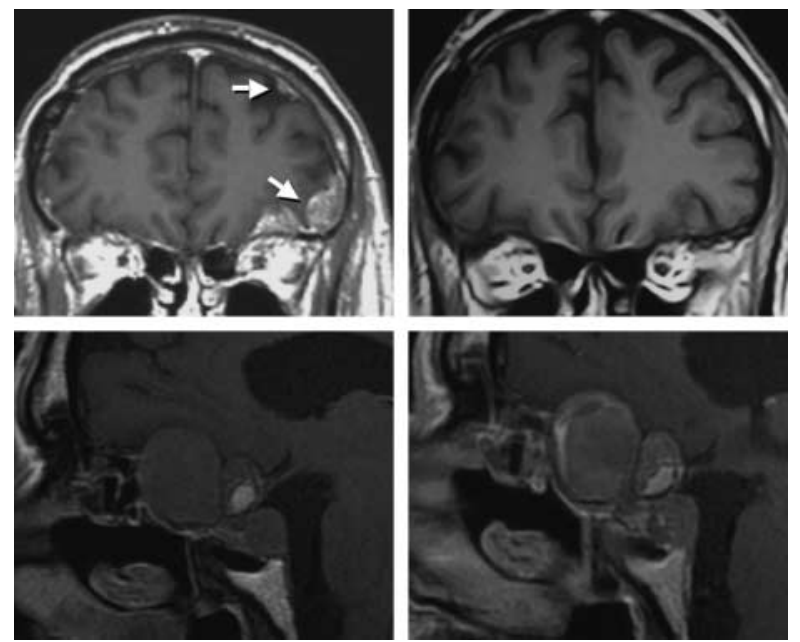

Figure 1 Coronal contrast-enhanced T1-weighted MRI of the brain of Patient \#2 obtained before (upper left panel) and 28 months after stopping 1-year treatment with temozolomide (upper right panel). Brain metastatic lesions (indicated by the arrows in the upper left panel) are no more evident on the post-treatment exam. Coronal contrast-enhanced T1-weighted MRI of the brain of Patient \#5 obtained before (lower left panel) and 12 months after treatment with temozolomide (lower right panel). No significant change in the tumor mass can be appreciated.

\section{Temozolomide treatment and follow-up visits}

After having obtained informed consent, temozolomide treatment was initiated according to the following scheme. Temozolomide was given orally at a dose of $150 \mathrm{mg} / \mathrm{m}^{2}$ per day for 5 days every 4 weeks for a maximum of 12 cycles. The dose was increased to $200 \mathrm{mg} / \mathrm{m}^{2}$ per day beginning with the second cycle, so long as there were no hematological toxic effects. Doses of the drug were rounded up to the nearest $5 \mathrm{mg}$ to accommodate capsule strength. The patients were instructed to fast $2 \mathrm{~h}$ before and $1 \mathrm{~h}$ after ingestion of the drug. In case of hematological toxicity, i.e. neutrophil and platelet counts lower than 1500 and $100000 / \mathrm{ml}$ respectively, or other non-hematological severe side effects, the start of the next cycle could be delayed for a maximum of 2 weeks, and the dose was reduced to $150 \mathrm{mg} / \mathrm{m}^{2}$ per day. Compliance with the treatment was ascertained by pill counts at each scheduled follow-up visit. The two patients with prolactinoma continued therapy with cabergoline at the same dose as done before temozolomide therapy.

Clinical examination and neurological evaluation were performed immediately before the administration of the next cycle of temozolomide. Blood counts and biochemical determination of hepatic and renal function were repeated on days 1 and 21 of each cycle, or as clinically indicated. MRI of the brain and of the spinal cord (in the patient with liquoral dissemination of the tumor) was repeated every three cycles of temozolomide or when clinically indicated. Measurement of the hormone directly secreted by the tumor (ACTH in four cases and PRL in the other two) was also repeated every 3 months. Basal pituitary function was assessed before and after 6 and 12 months of temozolomide treatment or when clinically indicated.

\section{Response criteria}

Response assessment was based on the measurable change in tumor size and hormone levels. Response was defined as reduction of at least $50 \%$ of tumor size, measured by the product of the greatest length and maximum width of all lesions, and normalization of hormone hypersecretion. Stable disease was defined as $<50 \%$ reduction in tumor size and hormone hypersecretion. Progressive disease was defined as an increase $>25 \%$ of tumor size, independent of hormone levels.

\section{Histological examination}

All the patients, except Patient \#6, underwent at least one neurosurgical procedure at our center. Surgical material was fixed in $10 \%$ buffered formalin and embedded in paraffin for light microscopy. Sections were stained with hematoxylin-eosin, the periodic acidSchiff (PAS), PAS-diastase, and Alcian technique. Immunohistochemical studies for anterior pituitary hormones and Ki-67 antigen were performed on $5 \mu \mathrm{m}$ thick paraffin sections using the streptavidin-biotinperoxidase-conjugated detection system, as described previously (15).

\section{Methylation analysis and immuno- histochemistry for MGMT}

Methylation-specific PCR was performed to determine the presence of methylation in the region of the MGMT promoter, as described previously (12). Amplification of the methylated DNA from a tumor was considered a positive result, while amplification of unmethylated DNA was scored as negative. MGMT promoter and protein expression were assessed by immunohistochemistry on formalin-fixed paraffin embedded tumor tissue, as described previously (12). Briefly, a mouse MAB (Clone MT23.2, Cat: MA3-16537, Affinity Bioreagents, Rockford, IL, USA) was used at a concentration of 1 in 8000 using a biotin-free detection system (DS9713 Leica Microsystems, Mount Waverley, Victoria, Australia) on an automated staining platform (BondMax autostainer Leica Microsystems). Only nuclear staining was examined, as cytoplasmic staining was considered nonspecific. Negative staining was defined as completely absent staining of more than $90 \%$ of tumor cells in the presence of a positive internal control (such as endothelial cells or lymphocytes) scattered throughout the slide. Staining of $10 \%$ of more tumor cells was considered positive. We emphasize that our interpretation required a positive internal control before 
considering a staining as informative. This is analogous to the approach used for interpreting immunohistochemistry data for DNA mismatch repair proteins in microsatellite unstable colon carcinoma (16). If a case stained repeatedly negative in the absence of a positive internal control, it was classified as non-informative. All the samples were examined by a single observer (A J G) who was blinded to the molecular and clinical data of the patients.

\section{Results}

\section{Tumor and hormone responses}

Four patients completed the 12 cycles of temozolomide treatment, as planned. Patient \#1 and Patient \#4 stopped the drug after 3 and 6 months respectively because of progression of disease. Two patients (Patient \#2 and Patient \#6) responded to temozolomide, while the remaining two patients (Patient \#3 and Patient \#5) had stable disease.

MRI of Patient \#1 showed further tumor growth 3 months after the start of temozolomide therapy. The patient complained of episodic minor nasal bleeding and impaired nasal respiration. Temozolomide treatment was stopped, and salvage radiotherapy and chemotherapy were initiated, as described below. Patient \#2 had a mild reduction in metastatic tissue already 3 months after starting the temozolomide therapy. At 12 months, MRI showed disappearance of all metastatic tissue. Similarly, ACTH and cortisol levels dropped from a baseline of $237 \mathrm{pg} / \mathrm{ml}$ and $159 \mathrm{ng} / \mathrm{ml}$ to $10 \mathrm{pg} / \mathrm{ml}$ and $13 \mathrm{ng} / \mathrm{ml}$ respectively requiring institution of glucocorticoid replacement therapy (Fig. 2). Patient \#3 had radiologically stable disease with initial, transitory hormonal response to temozolomide treatment: at 6 months, there was a slight reduction in the inferior part of the tumor, but at 12 months, this portion had re-expanded, and there was a questionable increase in the suprasellar portion of the tumor. Corresponding ACTH levels decreased from 6144 to $3580 \mathrm{pg} / \mathrm{ml}$ and then rose again to $6750 \mathrm{pg} / \mathrm{ml}$ (Fig. 2). Patient \#4 did not have any improvement of symptoms after temozolomide. At 6 months, MRI showed a mild increase in residual tumor in both cavernous sinuses and ACTH levels rising from 247 to $329 \mathrm{pg} / \mathrm{ml}$. Urinary free cortisol levels remained elevated, fluctuating between 1548 and $608 \mu \mathrm{g} / 24 \mathrm{~h}$ (normal values, $10-100 \mu \mathrm{g} / 24 \mathrm{~h}$ ). The patient was offered other treatments as detailed below. Patient \#5, who previously had progressive growth of his prolactinoma, showed an arrest of tumor growth. MRI after 12 cycles of temozolomide was unchanged in comparison with the pretreatment with MRI (Fig. 1). Moreover, PRL levels, which had previously shown an almost exponential rise, decreased from $2800 \mathrm{ng} / \mathrm{ml}$ to a nadir of $1232 \mathrm{ng} / \mathrm{ml}$ after the sixth cycle of temozolomide
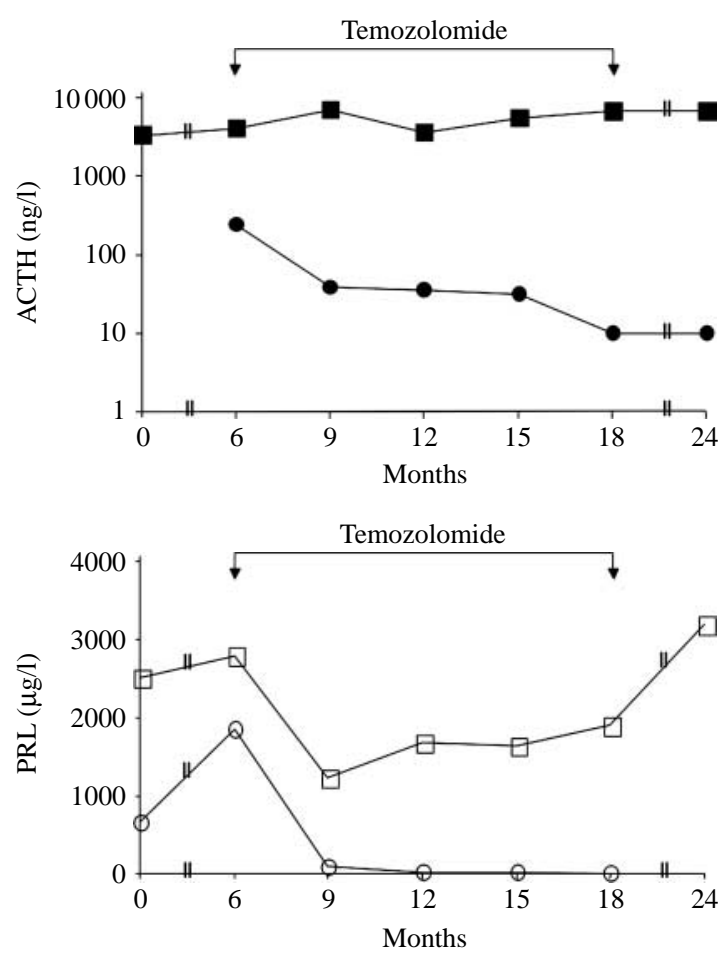

Figure 2 Hormone levels before, during, and after temozolomide treatment in four patients with pituitary carcinoma or atypical adenoma not responding to standard treatments. The upper panel shows the ACTH levels in Patient \#2 (solid circles) who had Cushing's disease and in Patient \#3 (solid squares) who had Nelson's syndrome. Note the logarithmic scale. The lower panel shows the PRL levels in Patients \#5 (open squares) and \#6 (open circles) who had a prolactinoma.

(Fig. 2). However, there was a trend toward rising PRL levels during the successive six cycles of temozolomide (Fig. 2). Patient \#6 had a prompt and dramatic response to temozolomide. The first MRI at 3 months already showed a marked reduction in tumor size, while PRL levels decreased from 1845 to $88 \mathrm{ng} / \mathrm{ml}$ (Fig. 2). Severe headache improved within 1 month, and the left sixth nerve palsy completely reversed after 6 months. At the end of the treatment, the tumor had further reduced in size, and the PRL levels had decreased to $8 \mathrm{ng} / \mathrm{ml}$ (Fig. 2).

\section{Further follow-up and treatments}

Follow-up treatments and disease status at last followup are summarized in Table 2. Patient \#1 was treated with a combination of fractionated radiotherapy, limited to the anterior nasal spaces to avoid summation with the two previous courses of radiation and chemotherapy with cisplatin and capecitabine. This new regimen induced a marked reduction in the tumor and improvement of nasal obstructive symptoms. However, progressive growth of residual disease was observed after 1 year of this regimen, and the patient was 
Table 2 Further treatments, control of tumor growth, and disease status at last follow-up in six patients who received temozolomide for a pituitary carcinoma or a locally aggressive pituitary adenoma.

\begin{tabular}{|c|c|c|c|c|c|}
\hline $\begin{array}{l}\text { Patient } \\
\text { number }\end{array}$ & $\begin{array}{l}\text { Tumor response } \\
\text { to temozolomide }\end{array}$ & Further treatments & $\begin{array}{c}\text { Tumor control } \\
\text { at last FU }\end{array}$ & Death & $\begin{array}{l}\text { Months to last } \\
\text { FU or death }\end{array}$ \\
\hline 1 & Progression & Rx, Chemotherapy ${ }^{a}$ & No & Yes & 30 \\
\hline 3 & Stable & TNS $^{\mathrm{b}}$ & No & No & 24 \\
\hline 4 & Progression & None & No & Yes & 11 \\
\hline 5 & Stable & TNS $^{\mathrm{b}}$ & No & No & 21 \\
\hline 6 & Response & None & Yes & No & 12 \\
\hline
\end{tabular}

FU, follow-up; Rx, fractionated radiotherapy; TNS, transsphenoidal surgery.

${ }^{a}$ Chemotherapy consisted of a course with cisplatin and capecitabine and a second course with gemcitabine.

${ }^{b}$ Both patients are now going to receive a trial with the somatostatin analog SOM 230.

switched to gemcitabine for 4 months, followed by etoposide for 8 months. The tumor was stable for 12 months but then progressed, and the patient died 4 months after the last chemotherapy, 30 months after entering the trial with temozolomide. Patient \#2 still needs replacement therapies for complete anterior pituitary deficiency 28 months after stopping temozolomide. His ACTH and cortisol levels of medication are $6.3 \mathrm{pg} / \mathrm{ml}$ and $20 \mathrm{ng} / \mathrm{ml}$ respectively. MRI does not show any residual metastatic disease (Fig. 1). Patient \#3 showed a mild increase in tumor volume on MRI 6 months after stopping temozolomide and developed new visual symptoms. She underwent another transsphenoidal surgery with the aim to relieve the optic pathway. This patient is now scheduled to receive a trial with SOM 230. After failure of temozolomide treatment, Patient \#4 was scheduled to undergo gamma knife radiosurgery to both cavernous sinuses and bilateral adrenalectomy because of accelerated progression of Cushing's disease. However, the patient had a spontaneous vertebral fracture before receiving the planned treatment. The successive clinical course was complicated by hypertension, hypokalemia, and infectious complications, leading to death 5 months after stopping temozolomide. MRI of Patient \#5 showed a slight increase in tumor size 6 months after stopping temozolomide. Sudden palsy of the right oculomotor nerve occurred, and the patient was admitted to our hospital to undergo another surgical debulking via a transsphenoidal approach, without improvement of the neurological defect. He is now undergoing a trial with SOM 230. Patient \#6 has concluded temozolomide treatment, as scheduled and is now beginning the follow-up period (Fig. 3).

\section{Response to temozolomide and MGMT status}

Patient \#1 had no sufficient viable tumoral tissue for immunohistochemistry or PCR analyses. PCR analysis of MGMT promoter methylation could be performed in only four samples (from Patients \#3, 4, 5, and 6) because of paucity of tumor tissue from Patient \#2, while immunohistochemistry for MGMT could be performed in five patients. In Patients \#2, 4, and 6, tumor tissue analyzed was prior to the commencement of temozolomide. However, for Patients \#3 and 5, the only tumor tissue available for study was following the completion of temozolomide treatment.

Methylation analysis of the MGMT promoter was negative in all the studied samples (Table 3), including Patient \#4 who showed no response to temozolomide. Immunohistochemistry for MGMT was negative in two samples (Patient \#2 who responded to the drug, and Patient \#5 who had arrest of tumor growth while on treatment). The immunohistochemistry result for Patient \#6, who also exhibited a complete response to temozolomide, showed negative tumor MGMT staining, but lacked positive staining of internal controls,

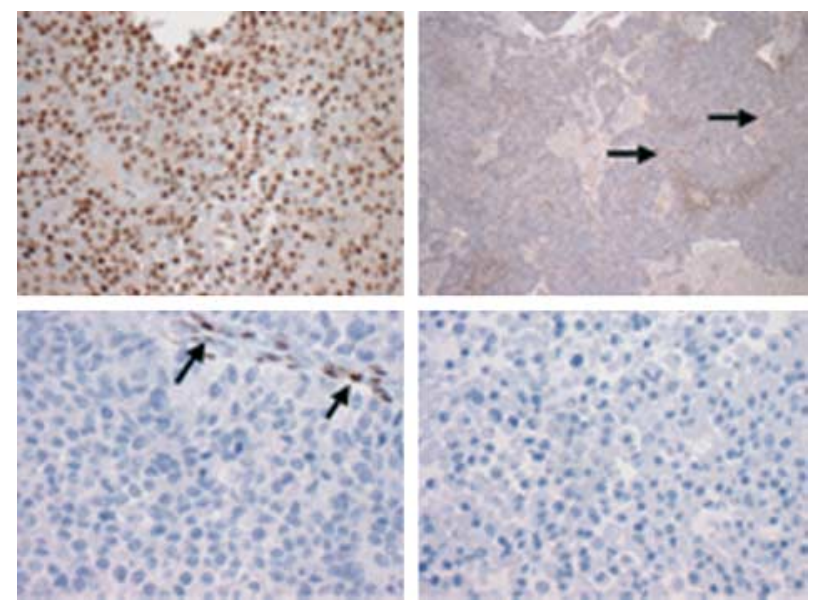

Figure 3 Immunohistochemistry for MGMT. Upper left panel: diffuse strong positive nuclear staining in tumor from Patient \#4 (original magnification $400 \times$ ). Upper right panel: there is negative staining in more than $90 \%$ of tumor cells from Patient \#5 (original magnification $100 \times$ ). It is therefore classified as negative. Note the positive staining in endothelial cells (arrows), which act as an internal positive control in areas where the tumor shows negative staining. Lower left panel: completely negative staining of tumor cells from Patient \#2 for MGMT. The presence of endothelial cells (arrows), which act as an internal positive control, is emphasized (original magnification $600 \times$ ). Lower right panel: negative staining for MGMT in tumor from Patient \#6. However, no internal positive control is evident, and it is therefore classified as non-informative by our classification (original magnification $600 \times$ ). 
Table 3 Histological characteristics of six patients treated with temozolomide because of pituitary carcinoma or atypical pituitary adenoma.

\begin{tabular}{llllll}
\hline $\begin{array}{l}\text { Patient } \\
\text { number }\end{array}$ & $\begin{array}{l}\text { IHC for pituitary } \\
\text { hormones }\end{array}$ & Ki-67 (\%) & $\begin{array}{l}\text { Methylation of } \\
\text { MGMT } \text { promoter }\end{array}$ & IHC for MGMT & $\begin{array}{l}\text { Disease response } \\
\text { to temozolomide }\end{array}$ \\
\hline 1 & ND & ND & ND & ND & Progression \\
$2^{\mathrm{a}}$ & ACTH & 1 & ND & Negative & Response \\
$3^{\mathrm{b}}$ & ACTH & 5 & Negative & Positive & Stable \\
4 & ACTH & 2.5 & Negative & Nesitive & Progression \\
$5^{\mathrm{b}}$ & PRL & 9 & Negative & Non-informative & Stable \\
6 & PRL & ND & Negative & Response \\
\hline
\end{tabular}

PRL, prolactin; IHC, immunohistochemistry; MGMT, methylguanine-DNA methyltransferase; ND, not done.

${ }^{\text {a }}$ The tissue sample was from a frontal metastasis.

${ }^{\mathrm{b}}$ Tissue sample was obtained from surgery performed 8 and 7 months after completing temozolomide treatment.

${ }^{\mathrm{c}}$ Tissue sample stained completely negative but lacked positive internal control.

making this result non-informative using our criteria. Patient \#3 (transient partial response) and Patient \#4 (no response) had strongly positive MGMT expression on immunohistochemistry.

\section{Discussion}

Previous case reports suggested that the alkylating agent temozolomide was very effective in the treatment of patients with pituitary carcinoma or locally aggressive pituitary adenoma (10-14, 17-19). Three patients with metastatic and progressive disease due to prolactinoma resistant to dopamine agonists (two cases) and LH-secreting tumor (one case) were alive and well 42, 28 , and 25 months after beginning temozolomide treatment $(10,11)$. Another patient with a mixed GH- and PRL-secreting carcinoma was treated for 23 months with temozolomide and was in remission of disease 3 years after terminating the treatment (17). Even though the clinical course of patients with pituitary carcinoma is not entirely predictable (4), the marked improvement observed in all four cases was attributable to temozolomide $(10,11,17)$. These results were remarkable, as several different chemotherapeutic regimens tried in the past in similar cases were reported to cause short-lasting responses in sporadic cases only $(20,21)$. Encouraged by these early findings, temozolomide was used with success in three of the four patients with locally aggressive pituitary adenoma (12-14), whose prognosis is usually poor because of locally rapid growth of the tumor.

However, case reports may overestimate the success rate of proposed interventions because of reporting bias. On the other hand, pituitary carcinomas are very uncommon (3), and atypical adenomas truly resistant to standard surgical, medical, and radiation therapy are not frequent too. Therefore, implementation of a formal, controlled study on this issue seems unlikely.

Our results were obtained in an unselected series of six consecutive patients with pituitary carcinoma or locally aggressive adenoma, thus, allowing one to gauge some information about the frequency, degree, and duration of tumoral response to temozolomide.
Two of the six patients (Patients \#2 and 6) had a long-lasting response to temozolomide as demonstrated by regression and normalization of ACTH and PRL hypersecretion respectively. The good response in the patient with dissemination of the pituitary tumor through the liquoral pathway is similar to that observed in the three index cases initially reported in the literature $(10,11)$. Two other patients (Patients \#1 and 4) had no benefit from therapy with temozolomide. At present, only few cases irresponsive to temozolomide have been reported in the literature $(12,22,23)$. The response in the other two patients (Patients \#3 and 5) is more difficult to interpret. Considering the rapid course of disease before and after temozolomide treatment, the arrest of tumor growth during therapy with the drug might be considered a worthy result. Both patients initially had a mild reduction in their hypersecreted hormone that later showed a trend to increase again despite continuing treatment with temozolomide. Supporting our results, two very recent studies of eight and seven patients reported good response to temozolomide treatment in three (38\%) and two cases $(29 \%)$ respectively $(22,23)$. In the latter study, four additional patients had stabilization of tumor growth during treatment with the drug, a response similar to that observed in Patients \#3 and 5 of our study. Raverot et al. (22) found that a trial of three cycles of treatment was sufficient to identify the patients who will eventually respond to the drug. Our results support this suggestion, as both responders already showed a clear reduction in tumor volume and hormone hypersecretion 3 months after beginning temozolomide treatment.

Recent data in patients with gliomas suggest the possibility to resume treatment with temozolomide in patients who had relapse of the tumor after stopping upfront treatment (24). Alternative regimens of temozolomide treatment, such as 3 weeks on and 1 week off, have also been explored to overcome chemoresistance of brain tumors $(25,26)$. Bush et al. (23) chose the 3 weeks on and 1 week off protocol to treat seven patients with aggressive pituitary tumors (including two carcinomas) because the high dose of temozolomide per unit time might theoretically deplete tumor cells of their MGMT more efficiently than the standard regimen. 
In this study, two of the seven patients had improvement of disease, four had stable disease, and the remaining one had progression of disease (23). However, at present, it remains unknown whether alternative regimens of temozolomide would work better than the standard regimen in patients with pituitary tumors.

The mechanism(s) by which temozolomide may act in pituitary tumors is still unknown. The patient with atypical PRL-secreting adenoma reported by Syro et al. (13) was subjected to another surgical procedure after successful treatment with temozolomide for 7 months. Histological analysis showed the presence of hemorrhages, necrosis, and fibrosis in comparison with the same tumor before temozolomide treatment (27), suggesting a potent antitumoral effect of the drug. This interpretation was confirmed by measuring the Ki-67 nuclear labeling index: it decreased from 40 to $60 \%$ in the pre-treatment specimen to $5 \%$ in the posttreatment sample (27). Neuronal transformation was also detected in the post-treatment specimen. It was supposed to indicate differentiation of the tumor, an event that may slow neoplastic growth (27). Recently, Sheehan et al. (28) reported the 'in vitro' effect of temozolomide on three pituitary adenoma cell lines. Temozolomide caused significant inhibition of cell proliferation at a concentration of $50 \mu \mathrm{M}$ in one cell line (AtT20) and $250 \mu \mathrm{M}$ in the other two cell lines (MMQ and GH3). Moreover, apoptosis significantly increased in all the cell lines after few hours of incubation (28).

More relevant is the search for prognostic factors able to predict which patient will benefit the most from this novel therapy. High levels of the DNA enzyme repair MGMT in tumor cells counteract the effects of alkylating agent (29). In patients with glioblastoma, epigenetic silencing of the MGMT gene by methylation of the MGMT promoter leads to low expression of MGMT in tumor cells and has been suggested as a predictive marker for a positive response to temozolomide (30, 31). A similar correlation with MGMT expression has been suggested for aggressive pituitary tumors (12, 17, 32). Indeed, absence or low levels of MGMT immunoreactivity predicted a positive response to temozolomide, while MGMT immunoreactivity in tumor cells was associated with a negative response to treatment $(12,17,32)$. Our data on the correlation between MGMT status and clinical response to temozolomide are incomplete because the results of MGMT staining were not available in one case, whereas in the other two cases the tested samples were those obtained after temozolomide treatment. It is unclear, at present, whether previous exposure to temozolomide can affect MGMT expression in tissue samples. Despite these drawbacks, MGMT status, as assessed by immunohistochemistry, provided some useful information on the clinical response to temozolomide. Indeed, both patients with a positive response to temozolomide had a negative tumor staining for MGMT (however, one lacked a positive internal control), while one patient with no response to temozolomide showed a strong positive staining for MGMT (no tissue was available for the other nonresponsive patient). It is more difficult to interpret the data in the remaining patients who had stabilization but not regression of disease during temozolomide treatment. The tissue samples from both the patients have been harvested after drug treatment: one had a negative and the other a positive staining. Heterogeneity of tumor MGMT expression is well described in glioblastoma (33), and we have also previously observed heterogeneous tumor staining in the same pituitary tumors (12). It is possible that the postive MGMT immunohistochemistry result in this latter patient indicates resistance to temozolomide acquired by selection of an MGMT expressing clone during temozolomide treatment. However, no correlation between MGMT staining and the response to temozolomide was detected in the other two largest series $(22,23)$. Further studies, possibly through a multicenter collaboration, would be necessary to clarify this issue. Methylation of the MGMT promoter is less likely to possess any predictive value, as it was negative all the four patients tested in our series and in all the seven patients in the series of Bush et al. (23), irrespective of the clinical response to temozolomide.

In conclusion, temozolomide treatment has a wide range of efficacy in patients with pituitary carcinoma or locally aggressive pituitary adenoma. Some patients have a dramatic response, as demonstrated by shrinkage or disappearance of the tumor and normalization of hormone hypersecretion. The response may persist even after termination of a 12-month treatment. Arrest of tumor growth may be achieved in other patients, but the effect may not be sustained. Continuous treatment with temozolomide in such cases should be explored in the future. Lastly, some patients do not show any response to temozolomide. Study of the expression of MGMT in tumor cells may aid in selecting those patients with the highest probability to benefit from this drug, as positive staining for MGMT seems to predict a lower chance of response.

\section{Declaration of interest}

The authors declare that there is no conflict of interest that could be perceived as prejudicing the impartiality of the research reported.

\section{Funding}

This research did not receive any specific grant from any funding agency in the public, commercial or not-for-profit sector.

\section{References}

1 Sellman WR, Laws ER, Scheithauer BW \& Carpenter SM. The occurrence of dural invasion in pituitary adenomas. Journal of Neurosurgery 198664 402-407. (doi:10.3171/jns.1986.64.3. 0402) 
2 DeLellis R, Lloyd RV, Heitz P \& Eng C (Eds). Tumors of Endocrine Organs (World Health Organization Classification of Tumors). Lyon: IARC Press, 2004.

3 Pernicone PJ, Scheithauer BW, Sebo TJ, Kovacs K, Horvath E, Young WF Jr, Lloyd RV, Davis DH, Guthrie BL \& Schoene WC. Pituitary carcinomas: a clinicopathological study of 15 cases. Cancer 199779 804-812. (doi:10.1002/(SICI)1097-0142(1997 0215)79:4<804::AID-CNCR18> 3.0.CO;2-3)

4 Kaltsas GA, Nomikos P, Kontogeorgos G, Buchfelder M \& Grossman AB. Diagnosis and management of pituitary carcinomas. Journal of Clinical Endocrinology and Metabolism 200590 3089-3099. (doi:10.1210/jc.2004-2231)

5 Ragel BT \& Couldwell WT. Pituitary carcinoma: a review of the literature. Neurosurgical Focus 200416 E7. (doi:10.3171/foc. 2004.16.4.8)

6 Newlands ES, Stevens MFG, Wedge SR, Wheelhouse RT \& Brock C. Temozolomide: a review of its discovery, chemical properties, preclinical development and clinical trials. Cancer Treatment Reviews 199723 35-61. (doi:10.1016/S03057372(97)90019-0)

7 Stupp R, Hegi ME, Mason WP, van den Bent MJ, Taphoorn MJ, Janzer RC, Ludwin SK, Allgeier A, Fisher B, Belanger K, Hau P, Brandes AA, Gijtenbeek J, Marosi C, Vecht CJ, Mokhtari K, Wesseling P, Villa S, Eisenhauer E, Gorlia T, Weller M, Lacombe D, Cairncross JG \& Mirimanoff RO; on behalf of the European Organization for Research and Treatment of Cancer Brain Tumour and Radiation Oncology Groups; the National Cancer Institute of Canada Clinical Trials Group. Effects of radiotherapy with concomitant and adjuvant temozolomide versus radiotherapy alone on survival in glioblastoma in a randomized phase III study: 5-year analysis of the EORT-NCIC trial. Lancet Oncology 200910 459-466. (doi:10.1016/S1470-2045(09)70025-7)

8 Agarwala SS \& Kirkwood JM. Temozolomide a novel alkylating agent with activity in the central nervous system, may improve the treatment of advanced metastatic melanoma. Oncologist 20005 144-151. (doi:10.1634/theoncologist.5-2-144)

9 Ekeblad S, Sundin A, Janson ET, Welin S, Granberg D, Kindmark H, Dunder K, Kozlovacki G, Orlefors H, Sigurd M, Oberg K, Eriksson B \& Skogseid B. Temozolomide as monotherapy is effective in treatment of advanced malignant neuroendocrine tumors. Clinical Cancer Research 200713 2986-2991. (doi:10.1158/1078-0432. CCR-06-2053)

10 Lim S, Shahinian H, Maya MM, Yong W \& Heaney AP. Temozolamide: a novel treatment for pituitary carcinoma. Lancet Oncology 20067 518-520. (doi:10.1016/S1470-2045 (06)70728-8)

11 Fadul CE, Kominsky AL, Meyer LP, Kingman LS, Kinlaw WB, Rhodes CH, Eskey CJ \& Simmons NE. Long term response of pituitary carcinoma to temozolomide. Journal of Neurosurgery 2006105 621-626. (doi:10.3171/jns.2006.105.4.621)

12 McCormack AI, McDonald KL, Gill AJ, Clark SJ, Burt MG, Campbell KA, Braund WJ, Little NS, Cook RJ, Grossman AB, Robinson BG \& Clifton-Bligh RJ. Low O(6)-methylguanine-DNA methyltransferase (MGMT) expression and response to temozolomide in aggressive pituitary tumours. Clinical Endocrinology 2009 71 226-233. (doi:10.1111/j.1365-2265.2008.03487.x)

13 Syro LV, Uribe H, Penagos LC, Ortiz LD, Fadul CE, Horvath E \& Kovacs K. Antitumor effects of temozolomide in a man with a large, invasive prolactin-producing pituitary neoplasm. Clinical Endocrinology 200665 552-553. (doi:10.1111/j.1365-2265. 2006.02653.x)

14 Neff LM, Weil M, Cole A, Hedges TR, Shucart W, Lawrence D, Zhu JJ, Tischler AS \& Lechan RM. Temozolomide in the treatment of an invasive prolactinoma resistant to dopamine agonists. Pituitary 200710 81-86. (doi:10.1007/s11102-007-0014-1)

15 Losa M, Barzaghi R, Mortini P, Franzin A, Mangili F, Terreni MR \& Giovanelli M. Determination of the proliferation and apoptotic index in adrenocorticotropin-secreting pituitary tumors: comparison between micro- and macroadenomas. American Journal of Pathology $2000156245-251$.
16 Lindor NM, Burgart LJ, Leontovich O, Goldberg RM, Cunningham JM, Sargent DJ, Walsh-Vockley C, Petersen GM, Walsh MD, Leggett BA, Young JP, Barker MA, Jass JR, Hopper J, Gallinger S, Bapat B, Redston M \& Thibodeau SN. Immunohistochemistry versus microsatellite instability in phenotypic colorectal tumours. Journal of Clinical Oncology 200220 1043-1048. (doi:10.1200/JCO.20.4.1043)

17 Hagen C, Schroeder HD, Hansen S, Hagen C \& Andersen M. Temozolomide treatment of a pituitary carcinoma and two pituitary macroadenomas resistant to conventional therapy. European Journal of Endocrinology 2009161 631-637. (doi:10. 1530/EJE-09-0389)

18 Mohammed S, Kovacs K, Mason W, Smyth H \& Cusimano MD. Use of temozolomide in aggressive pituitary tumors: case report. Neurosurgery $2009 \quad 64$ E773-E774. (doi:10.1227/01.NEU. $0000339115.12803 .4 \mathrm{E})$

19 Byrne S, Karapetis C \& Vrodos N. A novel use of temozolomide in a patient with malignant prolactinoma. Journal of Clinical Neuroscience 200916 1694-1696. (doi:10.1016/j.jocn.2009.05.013)

20 Kaltsas GA \& Grossman AB. Malignant pituitary tumours Pituitary 19981 69-81. (doi:10.1023/A:1009975009924)

21 Kaltsas GA, Mukherjee JJ, Plowman PN, Monson JP, Grossman AB \& Besser GM. The role of cytotoxic chemotherapy in the management of aggressive and malignant pituitary tumors. Journal of Clinical Endocrinology and Metabolism 1998 83 4233-4238. (doi:10.1210/jc.83.12.4233)

22 Raverot G, Sturm N, de Fraipont F, Muller M, Salenave S, Caron P, Chabre O, Chanson P, Cortet-Rudelli C, Assaker R, Dufour H, Gaillard S, François P, Jouanneau E, Passagia JG, Bernier M, Cornélius A, Figarella-Branger D, Trouillas J, Borson-Chazot F \& Brue T. Temozolomide treatment in aggressive pituitary tumors and pituitary carcinomas: a French Multicenter Experience. Journal of Clinical Endocrinology and Metabolism 201095 4592-4599. (doi:10.1210/jc.2010-0644)

23 Bush ZM, Longtine JA, Cunningham T, Schiff D, Jane JA Jr, Vance ML, Thorner MO, Laws ER Jr \& Lopes MB. Temozolomide treatment for aggressive pituitary tumors: correlation of clinical outcome with O6-methylguanine methyltransferase (MGMT) promoter methylation and expression. Journal of Clinical Endocrinology and Metabolism 2010. (doi:10.1210/jc.2010-0441)

24 Khasraw M, Bell D \& Wheeler H. Long-term use of temozolomide: could you use temozolomide for life in gliomas? Journal of Clinical Neuroscience 200916 854-855. (doi:10.1016/j.jocn. 2008.09.005)

25 Tosoni A, Franceschi E, Ermani M, Bertorelle R, Bonaldi L, Blatt V \& Brandes AA. Temozolomide three weeks on and one week off as first line therapy for patients with recurrent or progressive low grade gliomas. Journal of Neuro-Oncology $2008 \mathbf{8 9} 179-185$. (doi:10.1007/s11060-008-9600-y)

26 Wick W, Platten M \& Weller M. New (alternative) temozolomide regimens for the treatment of glioma. Neuro-Oncology 200911 69-79. (doi:10.1215/15228517-2008-078)

27 Kovacs K, Horvath E, Syro LV, Uribe H, Penagos LC, Ortiz LD \& Fadul CE. Temozolomide therapy in a man with an aggressive prolactin-secreting pituitary neoplasm: morphological findings. Human Pathology 200738 185-189. (doi:10.1016/j.humpath. 2006.07.014)

28 Sheehan J, Rainey J, Nguyen J, Grimsdale R \& Han S. Temozolomide-induced inhibition of pituitary adenoma cells. Journal of Neurosurgery 2010. (doi:10.3171/2010.4.JNS1024)

29 Gerson SL. MGMT: its role in cancer aetiology and cancer therapeutics. Nature Reviews. Cancer 20044 296-307. (doi:10. 1038/nrc1319)

30 Hegi ME, Diserens AC, Gorlia Hamou MF, de Tribolet N, Weller M, Kros JM, Hainfellner JA, Mason W, Mariani L, Bromberg JE, Hau P, Mirimanoff RO, Cairncross JG, Janzer RC \& Stupp R. MGMT gene silencing and benefit from temozolomide in glioblastoma. New England Journal of Medicine 2005352 997-1003. (doi:10.1056/ NEJMoa043331)

31 Gorlia T, van den Bent MJ, Hegi ME, Mirimanoff RO, Weller M, Cairncross JG, Eisenhauer E, Belanger K, Brandes AA, Allgeier A, 
Lacombe D \& Stupp R. Nomograms for predicting survival of patients with newly diagnosed glioblastoma: prognostic factor analysis of EORTC and NCIC trial 26981-22981/CE.3. Lancet Oncology 20089 29-38. (doi:10.1016/S1470-2045 (07)70384-4)

32 Kovacs K, Scheithauer BW, Lombardero M, McLendon RE, Syro LV, Uribe H, Ortiz LD \& Penagos LC. MGMT immunoexpression predicts responsiveness of pituitary tumors to temozolomide therapy. Acta Neuropathologica 2008115 261-262. (doi:10. 1007/s00401-007-0279-5)
33 Parkinson JF, Wheeler HR, Clarkson A, McKenzie CA, Biggs MT, Little NS, Cook RJ, Messina M, Robinson BG \& McDonald KL. Variation of O6-methyl-guanine-DNA methyltransferase (MGMT) promoter methylation in serial samples in glioblastoma. Journal of NeuroOncology 200887 71-78. (doi:10.1007/s11060-007-9486-0)

Received 17 September 2010

Accepted 24 September 2010 